\title{
AVALIAÇÃO DA QUALIDADE TECNOLÓGICA DE ENVOLTÓRIO NATURAL SUÍNO UTILIZADO NO PROCESSAMENTO DE LINGÜIÇA TOSCANA
}

\author{
Evaluation of the technological quality of natural pork casings used for \\ manufacture of Toscana sausage
}

\author{
Michelle Aparecida Lucini' ${ }^{1}$ Luciana Oliveira de Fariña ${ }^{2}$, Fabiana André Falconi ${ }^{3}$, Deisy Alessandra Drunkler ${ }^{4}$
}

\begin{abstract}
RESUMO
Neste trabalho, objetivou-se avaliar a qualidade de seis (6) diferentes fornecedores de envoltórios naturais suínos, utilizados para a elaboração de linguiça Toscana em um frigorífico localizado na região oeste do Paraná. As amostras foram codificadas como fornecedor 01, 02, 03, 04, 05 e 06, onde, com exceção do fornecedor 02, os demais foram de procedência nacional. As análises tecnológicas executadas nos envoltórios naturais foram a determinação da metragem, número de furos, número de fios por maço e a mensuração do calibre. Baseado nos resultados obtidos, o fornecedor 05 apresentou o pior desempenho. Não foi possível destacar um único fornecedor como o melhor para tal função. Sugere-se que a empresa em questão desenvolva formas de determinar o desvio padrão aceitável para os atributos, em especial, metragem, visando a melhor padronização do processo tecnológico.
\end{abstract}

Termos para indexação: Tripas, comprimento, fios, furos, fornecedores.

\section{ABSTRACT}

The aim of this work was to evaluate the technological quality of six (6) different natural swine casings for the elaboration of Toscana Sausage at a sausage manufacturer locate in the west region of Paraná State. The samples were codified as supplier 01, 02, 03, 04, 05, and 06 and with exception of supplier 02, they all had Brazilian origin. The technological analyses in the natural casings were the determination of length, number of punctures, thread number per bundle and bore measurement. Based on the results obtained, the supplier 05 presented the worst performance. It was not possible to determine an ideal supplier for this purpose. It is suggested that the company develops ways of determining the best acceptable standard deviation of these attributes, in special, the length, aiming at the best technological standardization of the process for the industry.

Index terms: Gut, length, thread, puncture, supplier.

(Recebido em 10 de janeiro de 2007 e aprovado em 6 de outubro de 2008)

\section{INTRODUÇÃO}

Desde remota antiguidade, o homem vem fabricando diferentes tipos de embutidos cárneos, na busca de conservar a carne e fornecer um produto à altura das aspirações do consumidor (Milani et al., 2003). Dentre os embutidos cárneos de amplo consumo no país, destaca-se a linguiça, em especial a Toscana, produto cru e curado obtido exclusivamente de carne suína, adicionado de gordura suína e ingredientes (Brasil, 2000). Este produto utiliza-se de tripas ou envoltórios naturais, que podem ser definidos como a subcamada da mucosa remanescente após a etapa de higienização de estômago, intestino, trato urinário ou reto (Sarantópoulos et al., 2001; Wijnker et al., 2006).

Apesar de envoltórios artificiais terem sido desenvolvidos, os naturais continuam a serem utilizados em razão das vantagens apresentadas, como o fato de serem comestíveis (Varnam \& Sutherland, 1998); elásticas e moldáveis, permeáveis à água e à fumaça (Ordónez et al., 2005), além do que a demanda dos consumidores por produtos ditos "naturais" requerem a produção de linguiças a partir de envoltórios naturais (Byun et al., 2001). No entanto, considera-se que a tripa natural possui fatores intrínsecos que podem afetar tanto o processamento quanto a qualidade do produto final, dentre eles o fato de serem altamente contaminadas, podendo ser portadoras de microrganismos patogênicos e saprófitos; falta-lhes homogeneidade de forma, tanto em comprimento e diâmetro, o que dificulta a padronização do produto; são pouco resistentes e podem portar defeitos (cortes, rupturas, nódulos parasitários, perfurações por insetos, putrefação,

\footnotetext{
${ }^{1}$ Tecnóloga em Alimentos e Ex-Discente do Curso de Pós Graduação em Controle de Qualidade, área de Concentração Alimentos - Colegiado de Farmácia - Centro de Ciências Médicas e Farmacêuticas/UNIOESTE/ Campus de Cascavel - Cascavel/ PR.

${ }^{2}$ Farmacêutica - Centro de Ciências Médicas e Farmacêuticas - Universidade Estadual do Oeste do Paraná - R. Universitária, 2069, Jardim Universitário - 85819-110 - Cascavel, PR - luleal32@yahoo.com.br

${ }^{3}$ Farmacêutica - Centro de Ciências Médicas e Farmacêuticas - Universidade Estadual do Oeste do Paraná - R. Universitária, 2069, Jardim Universitário - 85819-110 - Cascavel, PR - fafalconi@terra.com.br.

${ }^{4}$ Farmacêutica - Universidade Tecnológica Federal do Paraná - Av. Brasil, 4232, Parque Independência - 85884-000 - Medianeira, PR deisydrunkler@utfpr.edu.br
} 
ranço etc); requerem muito trabalho prévio ao seu emprego (lavagem com remoção do sal, higienização, etc) e proporcionam maior quebra de peso do produto (Pardi et al., 1996).

Inúmeros trabalhos preocupam-se, apenas, em avaliar a qualidade microbiológica dos envoltórios naturais e artificiais (Walls et al., 1993; Byun et al.,2001; Wijnker et al., 2006), e, quando muito, as características sensoriais e os parâmetros de textura dos produtos já embutidos (Bakker et al., 1999; Jo et al., 2002; Chawla et al., 2006) sem, contudo avaliarem as propriedades tecnológicas de fabricação referentes ao embutimento (padronização de produto, rendimento, entre outros).

As tripas naturais, em geral, são classificadas quanto a sua metragem, que, sob o ponto de vista tecnológico, pode ser obtida mediante a soma das metragens individuais das tripas que constituem o maço. Outro fator importante é o número de tripas abaixo de 04 metros, pois resultam em baixo rendimento, uma vez que não se consegue promover embutimento contínuo e, assim, uniformidade nos gomos (Nakamur, 2003).

A qualidade de um produto alimentício acabado, bem como a otimização da produção depende, fundamentalmente, da procedência e confiabilidade de seus componentes, ou seja, das matérias-primas, ingredientes e aditivos empregados. Exigências externas quanto a prazos de entrega cada vez mais curtos fazem com que as empresas analisem suas ferramentas disponíveis e atuem nos pontos do processo de fabricação que possam interferir o fluxograma normal.

Levando em consideração os fatores acima mencionados, conduziu-se este trabalho, com o objetivo de avaliar a qualidade tecnológica de 06 (seis) fornecedores de envoltórios naturais suínos para linguiça Toscana, quanto às características de calibre, número de furos, metragem e número de fios por maço, fatores estes que interferem no processo produtivo desse derivado cárneo.

\section{MATERIALE MÉTODOS}

\section{Obtenção e coleta das amostras}

O presente trabalho foi realizado num frigorífico localizado na região oeste do Paraná, que abate diariamente cerca de 1.700 suínos. Da carne obtida, $60 \%$ destina-se à exportação e $40 \%$ para mercado interno. Elabora, ainda, produtos industrializados, dentre eles, linguiça Toscana numa média de $52.000 \mathrm{~kg} /$ dia. Essa empresa forneceu os envoltórios para este estudo.

As amostras de tripa natural suína, destinadas à produção da linguiça Toscana foram coletadas manualmente das bambonas de acondicionamento, cuja quantidade seguiu o plano de recebimento da empresa (plano de amostragem), que está de acordo com a Instrução Normativa SRF no 191, de 16 de agosto de 2002 (Brasil, 2002), abrangendo os diferentes fornecedores desse envoltório natural.

As tripas naturais foram preparadas enxaguando-as em água potável e morna $\left(30^{\circ} \mathrm{C} \pm 5^{\circ} \mathrm{C}\right)$ para a retirada do sal, posteriormente, fez-se a desinfecção e amaciamento das mesmas em solução dióxido de cloro (VEROMAX®) 1,5\% à temperatura de $30^{\circ} \mathrm{C} \pm 5^{\circ} \mathrm{C}$ em tanques de aço inox, seguindose o enxágue em água potável à mesma temperatura de aplicação da solução sanificante. As amostras foram codificadas como fornecedor 01, 02, 03, 04, 05 e 06. Sendo os codificados como 01, 03, 04, 05 e 06 fornecedores de procedência nacional de tripa natural suína e o fornecedor 02 de procedência internacional desse envoltório.

\section{Análises tecnológicas}

Uma vez as amostras devidamente preparadas, foram submetidas às seguintes análises descritas pelo Procedimento Operacional Padrão da empresa:

a) Determinação da metragem: mediu-se o comprimento de cada unidade de tripa por maço por um colaborador treinado, por meio de uma régua graduada em aço inoxidável fixada na própria mesa de inspeção. A metragem obtida para cada tripa foi somada para cada maço, constituindo, dessa forma, a metragem total do mesmo. Ainda, o total do número de fios com metragem abaixo de 04 metros também foi computado por maço por meio da soma dos mesmos.

b) Determinação do número de fios por maço: um colaborador treinado contou unidade por unidade de tripa existente no maço.

c) Verificação do calibre e do número de furos: o envoltório analisado foi preenchido com água e disposto entre dois suportes com distância pré-definida para cada calibre a ser analisado. Nesta mesma etapa, procedeu-se a avaliação do número de furos uma vez que por estes passavam a água e permitia, dessa forma, a contagem visual dos mesmos.

\section{Análise estatística}

O experimento foi realizado em três repetições, onde os resultados obtidos foram submetidos à análise de variância (ANOVA/ MANOVA) e quando detectada diferença significativa ao nível de $5 \%$ de probabilidade foram submetidos ao Teste de Tukey, utilizando para tal o programa Statistica (Statsoft, 1998).

\section{RESULTADOS E DISCUSSÃO}

Ao avaliar os fornecedores de envoltórios naturais de suínos quanto à metragem (Figura 1 ), foi verificado que 0 fornecedor 06 diferiu significativamente $(p<0,05)$ dos demais 
fornecedores por possuir maior metragem $(98,26 \pm 18,02 \mathrm{~m})$, e este valor está dentro da média para o maço de tripa natural de suíno que é de 91,4 metros (Ockerman, 2006). Os demais fornecedores não diferiram entre si estatisticamente, variando de 86,85 $\pm 4,53 \mathrm{~m}$ (fornecedor 02) a 89,61 $\pm 3,42 \mathrm{~m}$ (fornecedor 05) $(\mathrm{p}>0,05)$. Apesar do fornecedor 06 ter apresentado maior metragem, apresentou o maior Coeficiente de Variação (18,33\%) quando comparado aos demais fornecedores que variaram entre $1,37 \%$ (fornecedor 03 ) a 5,22\% (fornecedor 02), o que não é viável para o processamento tecnológico, pois, segundo Picchi (2004), as tripas naturais suínas que apresentam maços padronizados garantem a obtenção de gomos uniformes e maior rapidez no processo.

Tripas ou envoltórios com metragem igual ou superior a 4 metros apresentam maior continuidade durante o embutimento, ou seja, menor número de paradas da embutideira durante esta etapa de elaboração, resultando em maior rendimento técnico. Dentre os fornecedores avaliados, verificou-se que o fornecedor 05 foi o que apresentou maior número de fios abaixo de 4 metros $(2,74$ $\pm 1,64$ fios), enquanto que os demais não diferiram estatisticamente entre si ( $\mathrm{p}>0,05)$ (Figura 2).

Em se tratando ainda da avaliação do requisito metragem, destaca-se a quantidade de fios por maço, pois, a soma da metragem dos fios resulta no comprimento total do envoltório. Analisando a Figura 3 na comparação entre os fornecedores de envoltórios naturais suínos, e levandose em consideração que todos apresentaram valores mínimos e máximos próximos, o único fornecedor que apresentou diferença significativa $(\mathrm{p}<0,05)$ em relação aos demais foi o de número 05 , possuindo maior número de fios por maço $(13,26 \pm 2,07$ fios/ maços $)$.

Todavia, este valor atingido pelo fornecedor 05 , maior número de fios por maço, não foi favorável, pois, anteriormente, ele também foi o que atingiu maior número de fios abaixo de 4 metros, sendo assim, pode apresentar um baixo rendimento durante o embutimento.

Falando-se em rendimento, outro fator importante durante o embutimento é a resistência da tripa que deve ser forte o suficiente para resistir à pressão durante o embutimento e demais etapas do processo (Picchi, 2004). Avaliando-se a Figura 4 no quesito número de furos nos envoltórios naturais suínos, verificou-se que o fornecedor 01 apresentou o pior desempenho diferindo significativamente $(\mathrm{p}<0,05)$, ou seja, o maior número de furos em relação aos demais $(1,52 \pm 1,58$ furos), indicando que o envoltório não possui uma boa resistência ao embutimento o que acarreta maior lentidão e quebra técnica durante o processo de embutimento. No entanto, os demais fornecedores não diferiram entre si em relação a este atributo $(\mathrm{p}>0,05)$.

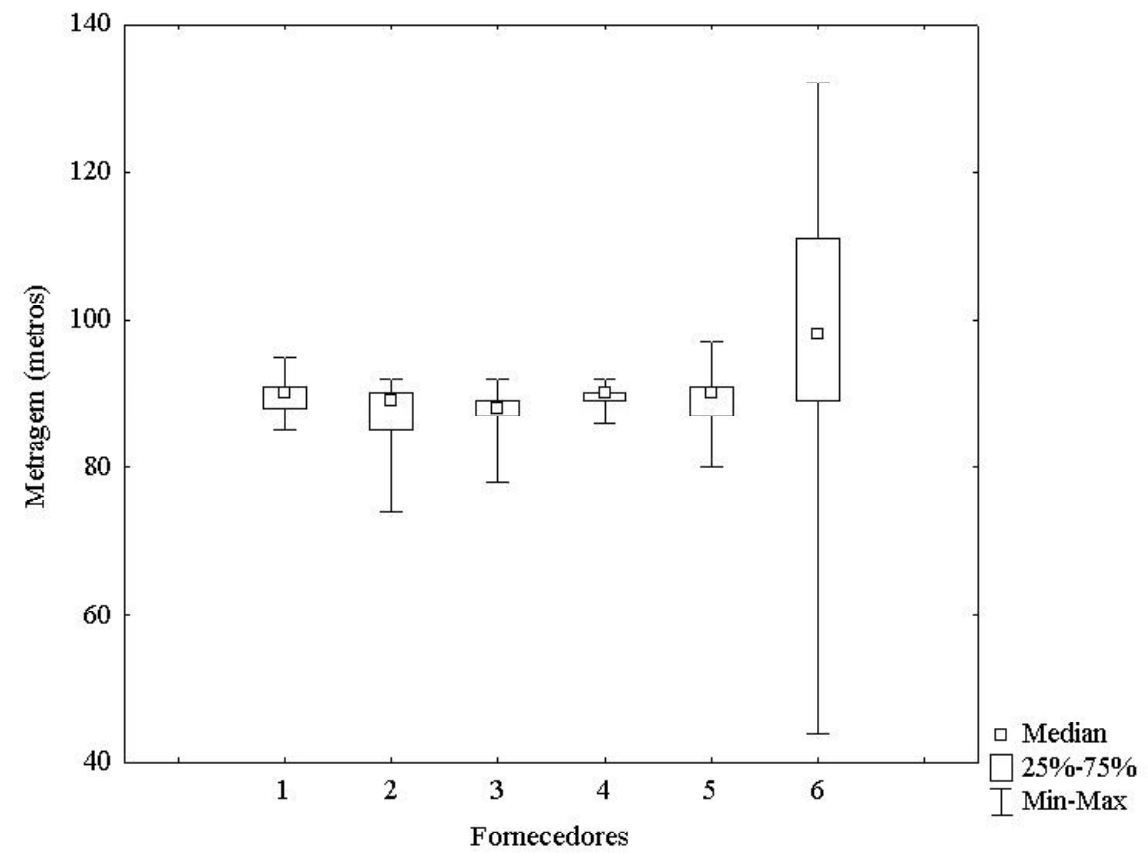

Figura 1 - Metragem (metros) dos envoltórios naturais de suínos empregados na elaboração de linguiça Toscana. *

* Média de 03 (três) repetições. 


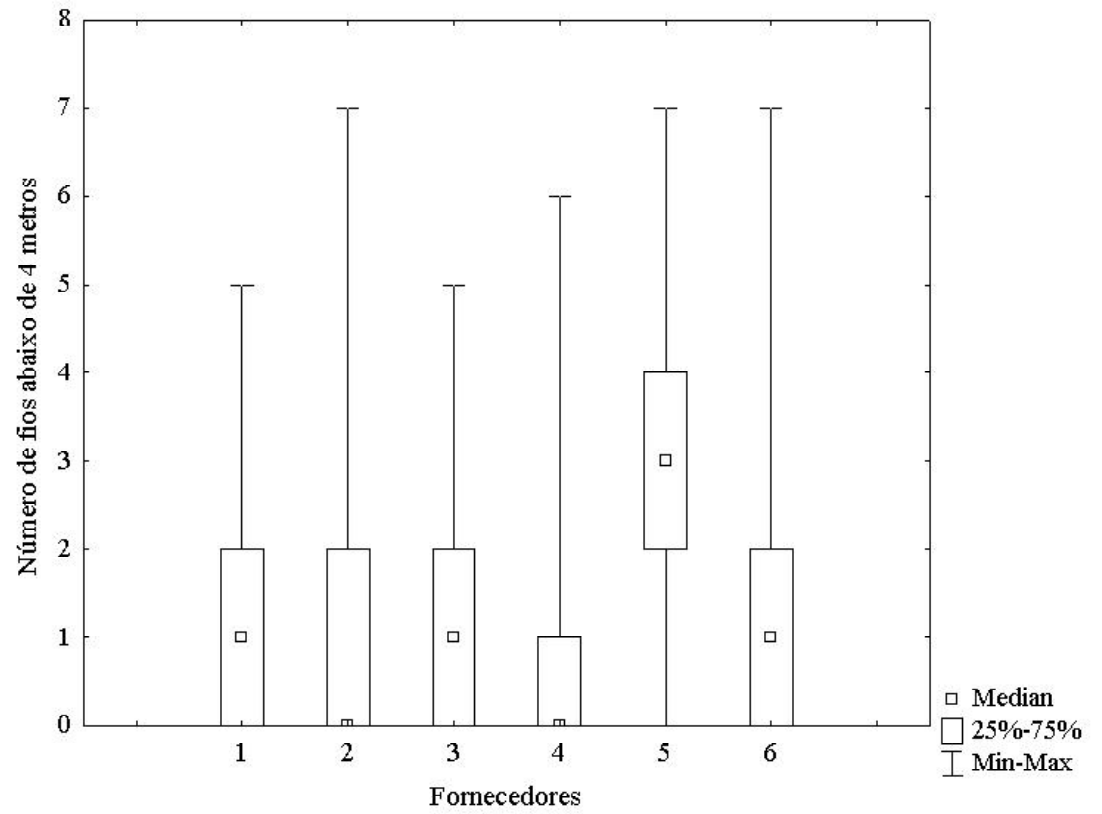

Figura 2 - Número de fios abaixo de 4 metros dos envoltórios naturais de suínos empregados na elaboração de lingüiça Toscana*

* Média de 03 (três) repetições.
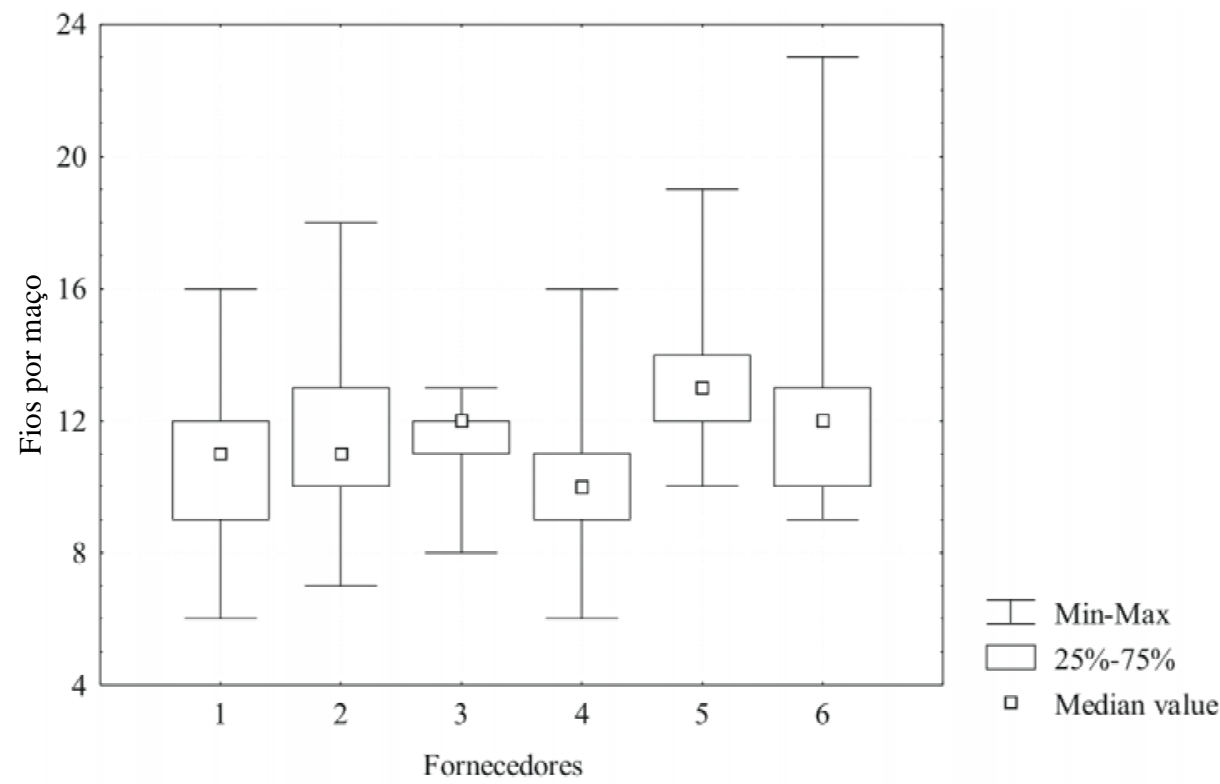

Figura 3 - Número de fios por maço de tripas naturais de suínos empregados na elaboração de linguiça Toscana. * * Média de 03 (três) repetições. 
Sequencialmente aos testes realizados, fez-se também a determinação do diâmetro das tripas (calibre); sendo esse quesito dependente da procedência da tripa, constituindo exigência normal para a padronização, a fim de que o envoltório desempenhe sua função adequadamente (Picchi, 2004), uma vez que equipamentos modernos de embutimento requerem que as tripas apresentem calibre uniforme para se obter uma adequada maquinabilidade (Ockerman, 2006). Os resultados obtidos na mensuração dos calibres dos envoltórios naturais suínos estão expostos na Tabela 1.

Verificou-se que todos os fornecedores de tripas suínas tiveram variação nos calibres, característica esta intrínseca aos envoltórios naturais (Ordónez et al., 2005). Percebe-se que o fornecedor que manteve maior porcentual do calibre $32 / 36 \mathrm{~mm}$ de maior demanda para o processo tecnológico de fabricação de linguiça Toscana (Pichi, 2004) foi o fornecedor 01 , seguido pelos fornecedores 04 e 03 .

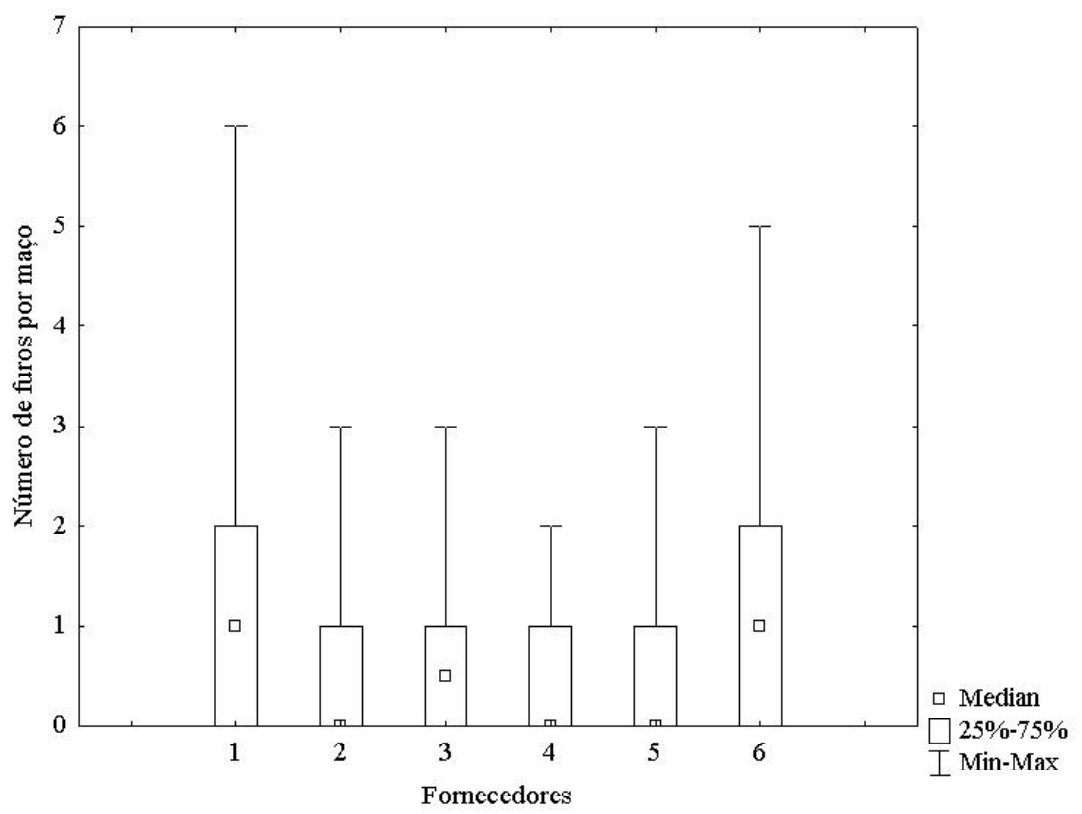

Figura 4 - número de furos por maço em tripas naturais de suínos empregados na elaboração de linguiça Toscana. *

* Média de 03 (três) repetições.

Tabela 1 - porcentagem média, de três repetições, obtida na mensuração do calibre (mm) das tripas naturais suínas empregadas na elaboração de linguiça Toscana.*

\begin{tabular}{ccccccc}
\hline & \multicolumn{7}{c}{ Fornecedores } \\
\cline { 2 - 7 } Calibres & F 01 & F 02 & F 03 & F 04 & F 05 & F 06 \\
\hline $32 / 36$ & 62,00 & 43,02 & 53,06 & 58,33 & 30,61 & 44,73 \\
$32 / 34$ & 18,63 & 29,06 & 10,20 & 13,88 & 42,85 & 7,89 \\
$32 / 38$ & 3,10 & 0 & 4,08 & 11,11 & 0 & 26,31 \\
$34 / 36$ & 4,65 & 1,16 & 16,32 & 8,33 & 2,04 & 2,66 \\
$30 / 34$ & 4,65 & 16,27 & 0 & 0 & 16,32 & 0 \\
$30 / 36$ & 6,97 & 5,81 & 12,24 & 2,80 & 6,12 & 15,78 \\
$30 / 32$ & 0 & 4,68 & 0 & 0 & 0 & 2,63 \\
$34 / 38$ & 0 & 0 & 4,1 & 5,55 & 0 & 0 \\
$30 / 38$ & 0 & 0 & 0 & 0 & 2,06 & 0 \\
\hline
\end{tabular}

\section{F: fornecedor.}




\section{CONCLUSÃO}

Em relação aos resultados obtidos para os atributos avaliados nos envoltórios naturais suínos destinados à elaboração de lingüiça Toscana, foi verificado que o pior desempenho foi apresentado pelo fornecedor 05 . No entanto, não foi possível destacar um único fornecedor como o melhor para tal função. Sugere-se que a empresa em questão desenvolva formas de determinar o coeficiente de variação aceitável para os atributos, em especial, metragem, visando a melhor padronização do processo tecnológico.

\section{REFERÊNCIAS BIBLIOGRÁFICAS}

BAKKER, W.A.M.; HOUBEN, J.H.; KOOLMEES, P.A.; BINDRICH, U.; SPREHE, L. Effect of initial mild curing, with additives, of hog and sheep sausage casings on tehir microbial quality and mechanical properties afetr storage at difference temperatures. Meat Science, Barking, v.51, p.163-174, 1999.

BRASIL. Ministério da Agricultura, Pecuária e Abastecimento. Instrução Normativa n. ${ }^{\circ}$ 04, de 31 de março de 2000. Dispõe sobre os regulamentos técnicos de identidade e qualidade de carne mecanicamente separada, de mortadela, e de lingüiça e de salsicha, em conformidade com os anexos desta instrução normativa. Brasília, DF, 2000.

BRASIL. Ministério da Agricultura, Pecuária e Abastecimento. Instrução Normativa SRF n. ${ }^{0}$ 191, de 16 de agosto de 2002. Dispõe sobre verificação física de bens importados destinados à exportação. Brasília, DF, 2002.

BYUN, M.W.; LEE, J.W.; JO, C.; YOOK, H.S. Quality properties of sausage made with gamma-irradiated natural pork and lam casing. Meat Science, Barking, v.59, p.223-228, 2001.

CHAWLA, S.P.; CHANDER, R.; SHARMA, A. Safe and shelf-stable natural casing using hurdle technology. Food control, Guildford, v.17, p.127-131, 2006.

JO, C.; LEE, J.W.; CHO, K.H.; YOOK, H.S.; BYUN, M.W. Quality properties of sausage made with gamma irradiated natural casing from intetine of pork or lamb. Radiation Physics and Chemistry, Oxford, v.63, p.365367, 2002.
MILANI, L.I.G.; FRIES, L.L.M.; PAZ, P.B.; BELLE, M.; TERRA, N.N. Bioproteção de Lingüiça de Frango. Ciência e Tecnologia de Alimentos, Campinas, v.23, n.2, p.161-166, maio/ago. 2003.

NAKAMUR, A. Tripas: segurança e qualidade para embutidos. Revista Nacional da Carne, São Paulo, n.317, jul. 2003. Disponível em: <htttp://WWw.dipemar.com.bry. Acesso em: 31 set. 2006.

OCKERMAN, H.W. Natural casings. Animal Sciences Research and Reviews, n.156, 2006. Disponível em:

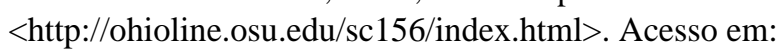
16 out. 2006

ORDÓNEZ, J.A.; RODRIGUES, M.I.C.; ÁLVAREZ, L.F.; SANZ, M.L.G.; MINGUILLÓN, G.D.G.F.; PERALES, L.H.; CORTECERO, M.D.S. Tecnologia de alimentos. Porto Alegre: Artmed, 2005. v.2, 279p.

PARDI, C.L.; SANTOS, F.I.; SOUZA, R.E.; PARDI, S.H. Ciência, higiene e tecnologia da carne. Goiânia: UFG, 1996. v.2, 1110p.

PICCHI, V. Tripas naturais de bovinos. Revista Nacional da Carne, São Paulo, n.334, dez. 2004. Disponível em: 4http://Www.dipemar.com.br

SARANTÓPOULOS, C.I.G.L.; OLIVEIRA, L.M.; CANAVESI, E. Requisitos de conservação de alimentos em embalagens flexíveis. Campinas: CETEA, 2001.

STATSOFT. Statistica for Windows: release 5.1. Tulsa, 1998. Software.

VARNAM, A.H.; SUTHERLAND, J.P. Carne y productos cárnicos. Zaragoza: Acribia, 1998.

WALLS, I.; COOKE, P.H.; BENEDICT, R.C.; BUCHMAN, R.L. Factors affecting attachment of Salmonella typhimurium to sausage casings. Food Microbiology, London, v.10, p.387-393, 1993.

WIJNKER, J.J.; KOOP, G.; LIPMAN, L.J.A. Antimicrobial properties of salt $(\mathrm{NaCl})$ used for the preservation of natural casings. Food Microbiology, London, v.23, p.657$662,2006$. 